\title{
TECHNICAL AND ORGANIZATIONAL IMPROVEMENTS OF PACKAGING PRODUCTION PROCESS
}

\author{
Anna Rudawska', Nadežda Čuboňova ${ }^{2}$, Kamila Pomarańska', Dana Stančeková3 , Arkadiusz Gola ${ }^{4}$ \\ 1 Department of Production Engineering, Faculty of Mechanical Engineering, Lublin University of Technology, \\ Nadbystrzycka Street 36, 20-618 Lublin, Poland, e-mail: a.rudawska@pollub.pl \\ 2 Department of Automation and Production Systems, Faculty of Mechanical Engineering, University of Žilina, \\ Univerzitná 8215/1, 01026 Žilina Slovak Republic, e-mail: nadezda.cubonova@fstroj.uniza.sk \\ ${ }^{3}$ Department of Machining and Production Technologies, Faculty of Mechanical Engineering, University of \\ Žilina, Univerzitná 8215/1, 01026 Žilina Slovak Republic, e-mail: dana.stancekova@fstroj.uniza.sk \\ ${ }^{4}$ Department of Enterprise Organization, Lublin University of Technology, Nadbystrzycka Street 38, 20-618 \\ Lublin, Poland, e-mail: a.gola@pollub.pl
}

Received: 2016.03.25

Accepted: 2016.04.25

Published: 2016.06.01

\begin{abstract}
Due to customer driven economies, today's world markets are characterized by high fluctuations in market demand and frequent arrival of new technologies and new products. To stay competitive in such markets manufacturing companies require continuous improvements both in technical and organizational areas of their activity. The paper presents results of the diagnosis provided in the manufacturing area of the company producing cardboard packages and recommendations to make the production process more efficient. Especially, among the proposed technical and organizational recommendations the most important ones are: automation of certain elements of the production process and changes in production plant layout.
\end{abstract}

Keywords: packaging, production process, improvements, efficiency, lay-out, automation.

\section{INTRODUCTION}

Any manufacturing company's goal is to satisfy the social demand by producing particular goods or providing particular services $[4,10$, $11,14]$. Each organisational unit and service is geared towards aiding the production process and striving at making it the most effective [5-8]. Organisational efforts are what provides assistance and reinforces these objectives $[1,3,12]$. Company owners must face the challenges of the market, such as: globalisation, increasing competition, rapid introduction of new technologies, not to mention growing consciousness of consumers, who demand better quality products and services $[9,13,16]$. This means manufacturers must act more time- and cost-effectively $[2,15,18]$. Organisations must constantly analyse the market, react to any turbulence that occurs, maintain close direct contact with their customer, promote initiative of their employees and become specialists in a particular area of activity $[17,19]$.

\section{DESCRIPTION OF THE COMPANY}

\section{The scope of operation}

Established in 1992, INTERPAK has always been working in the packaging industry, producing corrugated cardboard packages. The company offers a selection of cardboard packages securing the transported or stored goods. INTERPAK's area of speciality is the production of the following packages:

- unit packages for products sold in retail,

- collective packages used in transport and storing, 
a)

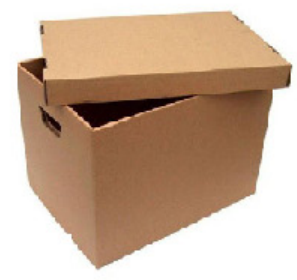

c)

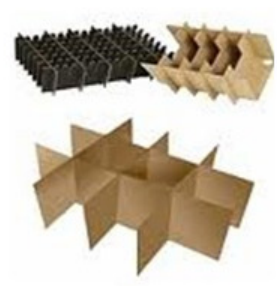

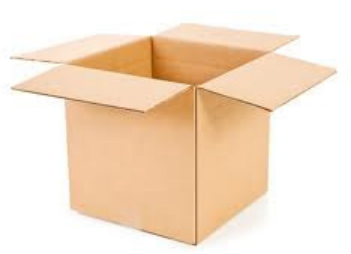

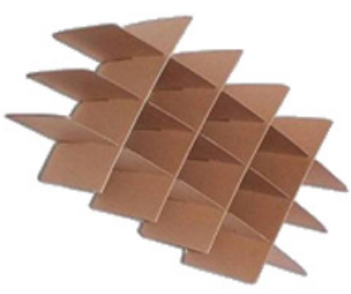

b)
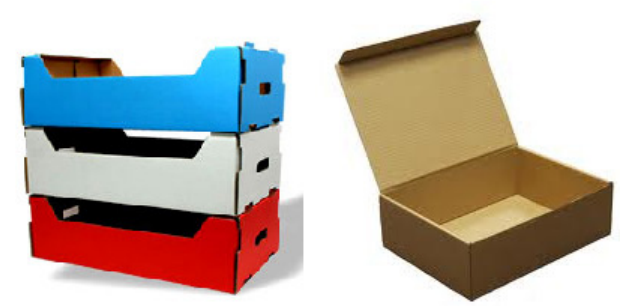

d)
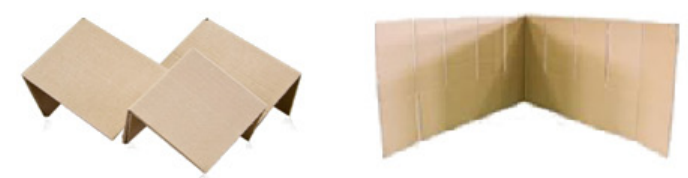

e)

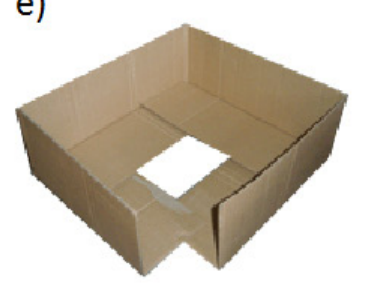

Fig. 1. Products: a) slotted-type box, b) die-cut box, c) lattice, d) divider, e) sleeve

- transport packages for goods transported or stored in bulk or in unit (collective) packages.

The manufacturer operates in the Lublin region, providing for the individual as well as institutional customer. Major customers of INTERPAK are companies of the foodstuff and chemical industries.

By definition INTERPAK is regarded as an SME (small and medium-sized enterprise). At present the company has 9 employees, and therefore is a small enterprise.

\section{Product assortment}

INTERPAK produces the following types of corrugated cardboard packaging:

- slotted-type, stitched or glued (Fig. 1a),

- die-cut - different designs (Fig. 1b),

- interior fitments, e.g. lattices (Fig. 1c), dividers (Fig. 1d), sleeves (Fig. 1e).

The company can produce large-size packages and blanks. The offer includes 3- and 5-layer boxes, glued or stitched. The customer can order printed and multi-colour packaging.

\section{PACKAGING PRODUCTION PROCESS}

The cardboard packaging production process consists in transforming the stock material, i.e. corrugated cardboard sheets, into the final product, which is foodstuff and chemical products packaging.

The production is divided into five stages:

- inspection and preparation of cardboard sheets,

- working the material with machines or by hand,

- finishing,

- stacking the finished product on pallets,

- transporting the finished product to warehouse.

Depending on the set type of packaging (clear or printed) and the type of supplied semi-finished product, a different job sequence is applied.

\section{Production of clear corrugated cardboard packaging}

Particular stages (operations) and jobs of the clear packaging production process are described in Table 1. 
Table 1. Clear corrugated cardboard packaging production

\begin{tabular}{|c|c|c|}
\hline \multicolumn{2}{|c|}{$\begin{array}{l}\text { Stage of packaging } \\
\text { production }\end{array}$} & Activity \\
\hline 1. & Preparation & Checking sheet dimensions \\
\hline \multirow{4}{*}{2} & \multirow{4}{*}{$\begin{array}{l}\text { Machine or hand } \\
\text { working }\end{array}$} & $\begin{array}{l}\text { Setting the machine to a given } \\
\text { sheet format }\end{array}$ \\
\hline & & Loading the die \\
\hline & & Running the machine \\
\hline & & $\begin{array}{l}\text { Supervision of the production } \\
\text { process }\end{array}$ \\
\hline \multirow{3}{*}{3} & \multirow{3}{*}{ Finishing } & Quality control \\
\hline & & Discarding waste \\
\hline & & $\begin{array}{l}\text { Folding the packaging (stitching or } \\
\text { gluing if necessary) }\end{array}$ \\
\hline 4. & \multicolumn{2}{|c|}{ Stacking the finished products on pallets } \\
\hline 5. & \multicolumn{2}{|c|}{ Transport of the finished product to warehouse } \\
\hline
\end{tabular}

The preparation stage consists of checking the dimensions of the cardboard sheets. The worker must set the cylindrical or rotary press equipment according to the format of blanks. Next, a die is loaded (the pattern should be placed perpendicularly and its shape must correspond to the dimensions of a desired finished product). The machine is then started, and its work and product quality are constantly supervised by the worker. Next, the remaining cuttings are removed and the box is folded (and stitched or glued if necessary). Finally the product is stacked on a pallet and transported to the finished goods warehouse.

\section{Production of printed corrugated cardboard packaging}

Particular stages (operations) and jobs of the printed packaging production process are described in Table 2.

The sequence of actions in production of printed packaging is slightly different from the one presented in Table 1, because proper machine working must be preceded by printing job performed on blanks. First, paint must be supplied to the printer and the colours regulated. Properly printed and prepared sheets are placed into die-cutting equipment. Having loaded the die, the worker can start the machine and begin the production of coloured boxes. Analogically to the previous case, here too the process and quality of the product must be supervised. Finally the packaging should be stitched, glued or folded, placed on a pallet and sent to the finished goods warehouse.
Table 2. Printed corrugated cardboard packaging production

\begin{tabular}{|c|c|c|}
\hline \multicolumn{2}{|c|}{$\begin{array}{l}\text { Stage of packaging } \\
\text { production }\end{array}$} & Activity \\
\hline \multirow{3}{*}{1.} & \multirow{3}{*}{ Preparation } & Checking sheet dimensions \\
\hline & & Loading paint to printer \\
\hline & & Colour setting \\
\hline \multirow{5}{*}{2.} & \multirow{5}{*}{$\begin{array}{l}\text { Machine or hand } \\
\text { working }\end{array}$} & Printing on the blanks \\
\hline & & $\begin{array}{l}\text { Setting the machine to a given } \\
\text { sheet format }\end{array}$ \\
\hline & & Loading the die \\
\hline & & Running the machine \\
\hline & & $\begin{array}{l}\text { Supervision of the production } \\
\text { process }\end{array}$ \\
\hline \multirow{3}{*}{3.} & \multirow{3}{*}{ Finishing } & Quality control \\
\hline & & Discarding waste \\
\hline & & $\begin{array}{l}\text { Folding the packaging (stitching or } \\
\text { gluing if necessary) }\end{array}$ \\
\hline 4. & \multicolumn{2}{|c|}{ Stacking the finished products on pallets } \\
\hline 5. & \multicolumn{2}{|c|}{ Transport of the finished product to warehouse } \\
\hline
\end{tabular}

\section{Machine park}

The company's machine park is adjusted to the type of production. However, as a result of insufficient production expenses, the technical facilities require modernisation. Presented below is the description of machines and production equipment.

Flexographic machine (Fig. 2a) is a machine that performs printing on solid, corrugated cardboard of 3 or 5 layers. Printing is conducted directly on a rotary printer with water flexographic paint. The cardboard sheet is moved by a feeder with reciprocating motion transmission. A cardboard bending machine (Fig. 2b) performs longitudinal creases.

Slotter (Fig. 3a) is an efficient specialised tool used in the company for slotted-type box production. One of the major advantages of this machine is that it does not require the application of any additional dies, as it is equipped in a set of knives, which can be adjusted as per requirements. The slotter cuts out a flap, essential in cardboard gluing. Although the cardboard sheets are fed automatically from the feeder stack, the main disadvantage is that the blanks must be nested manually. Slotter is an ideal solution in mass production of slotted-type boxes, even when a number of diverse formats are required. The efficiency of the machine is approximately 3000 sheets per hour.

A roller die cutter (Fig. 3b) is another machine used in the analysed company. Relatively low price is among the advantages of this simple flat die machine. Used for die-cut box production, it offers a 

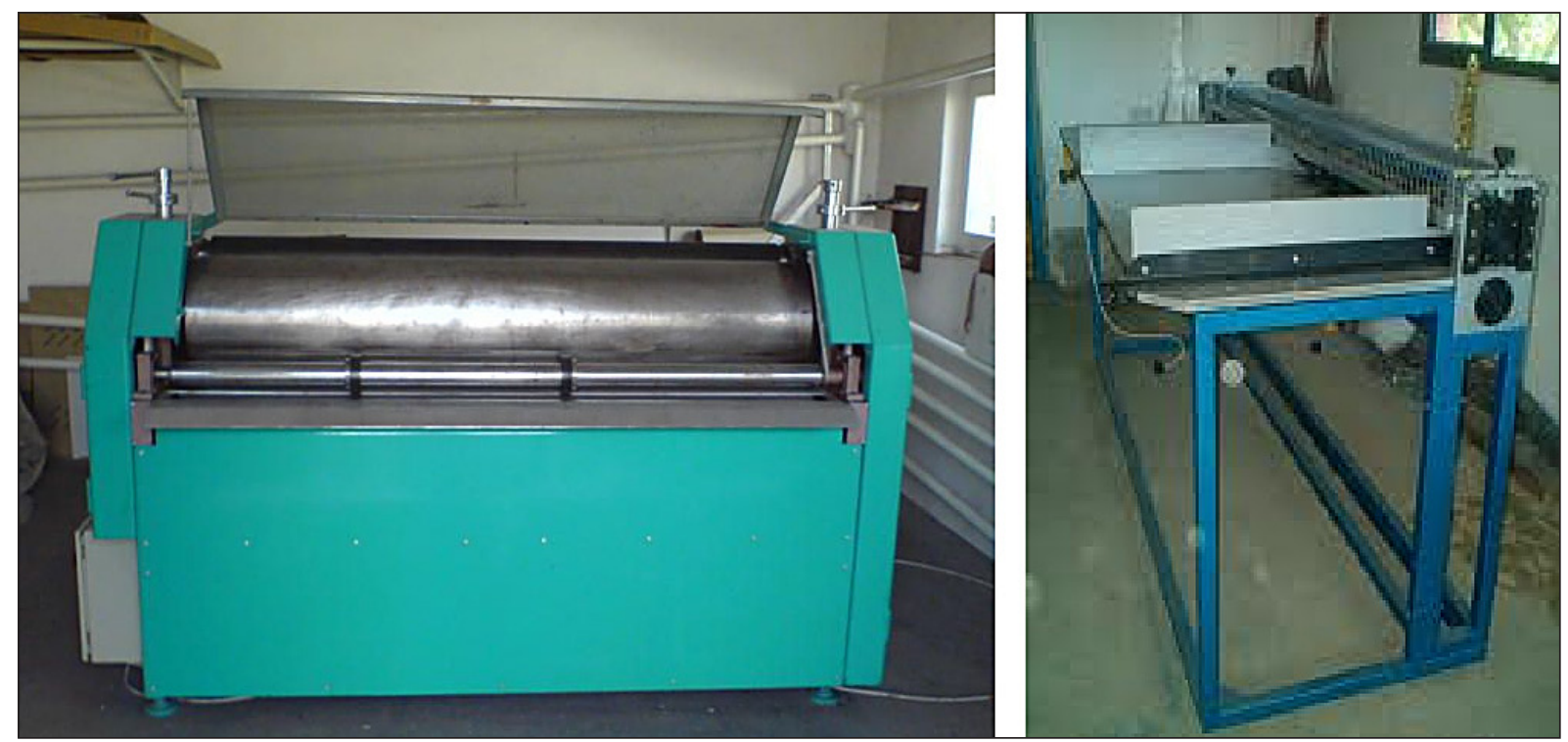

Fig. 2. Technical equipment: a) a printer, b) a cardboard bending machine

limited efficiency of 200-250 sheets per hour due to the necessity to load and remove cardboard manually. The machine is useful mainly in shortrun production of die-cut boxes, especially in the case when high flexibility in terms of forms is required. The machine is not suitable for the production of flap boxes, as it would require the change of die with every change of box type.

The technical equipment used at INTERPAK also includes a rotary die cutter (Fig. 4a), a highly-efficient machine, mainly for the production of die-cut boxes. The cutting is performed with rotary dies.

Working with the machine consists in loading cardboard into the automatic feed and removing a pallet with a stack of finished boxes from behind the machine. As the die cutter is synchronised with the feed, dies with minimum trim allow- ance are sufficient, thus the amount of waste cuttings is minimised, which is of great importance in large-quantity production. This fact marks a considerable advantage of this machine over the roller die cutter, which requires blanks of additional trim allowance, and earmarks the rotary die cutter as a proper solution for mass production. The machine's unsuitability for short series is furthermore highlighted by the necessity to use more expensive dies, making it cost-ineffective in small batches. Automated feed enables efficiency of 3000 sheets per hour.

A flat-wire stitcher (Fig. 4b) is a machine used at the facilities for joining corrugated cardboard with single or double wire stitching. The dimensions of the tool are: arm length $1400 \mathrm{~mm}$, operation height $1075 \mathrm{~mm}$. The machine enables stitching 2-5 layer cardboard sheets.
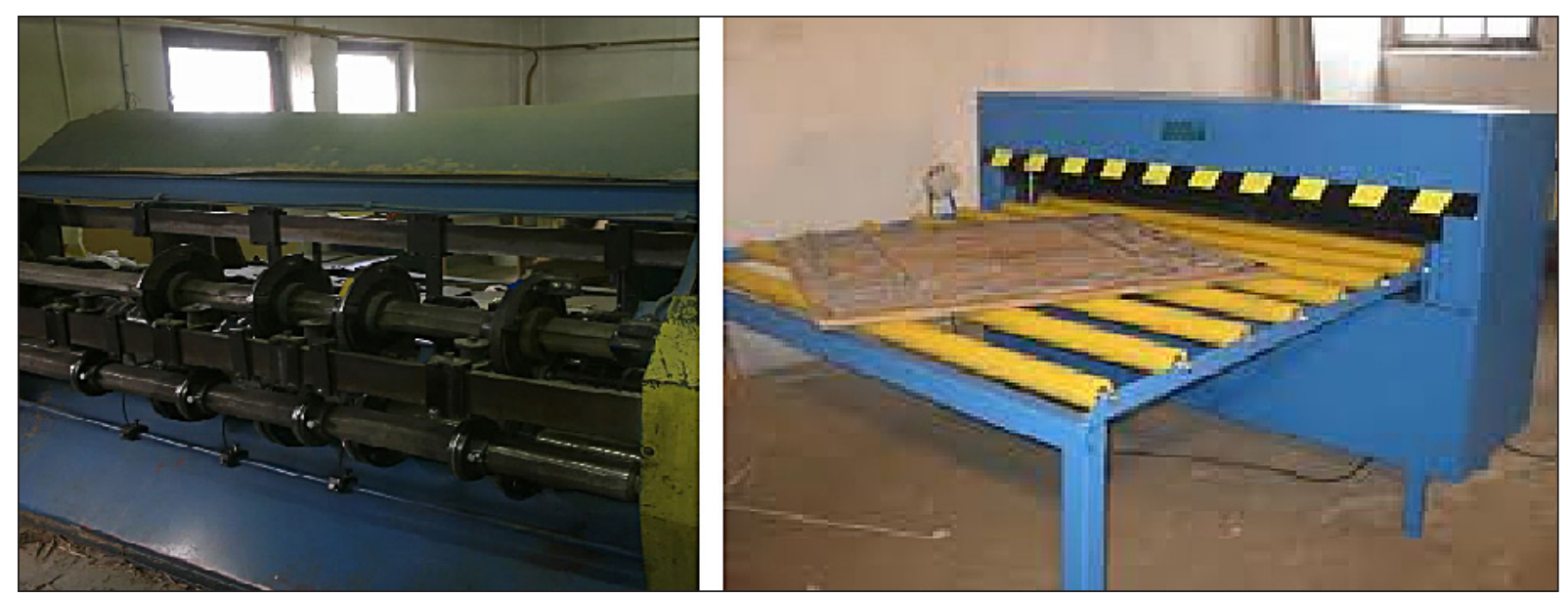

Fig. 3. Technical equipment: a) slotter, b) roller die cutter 


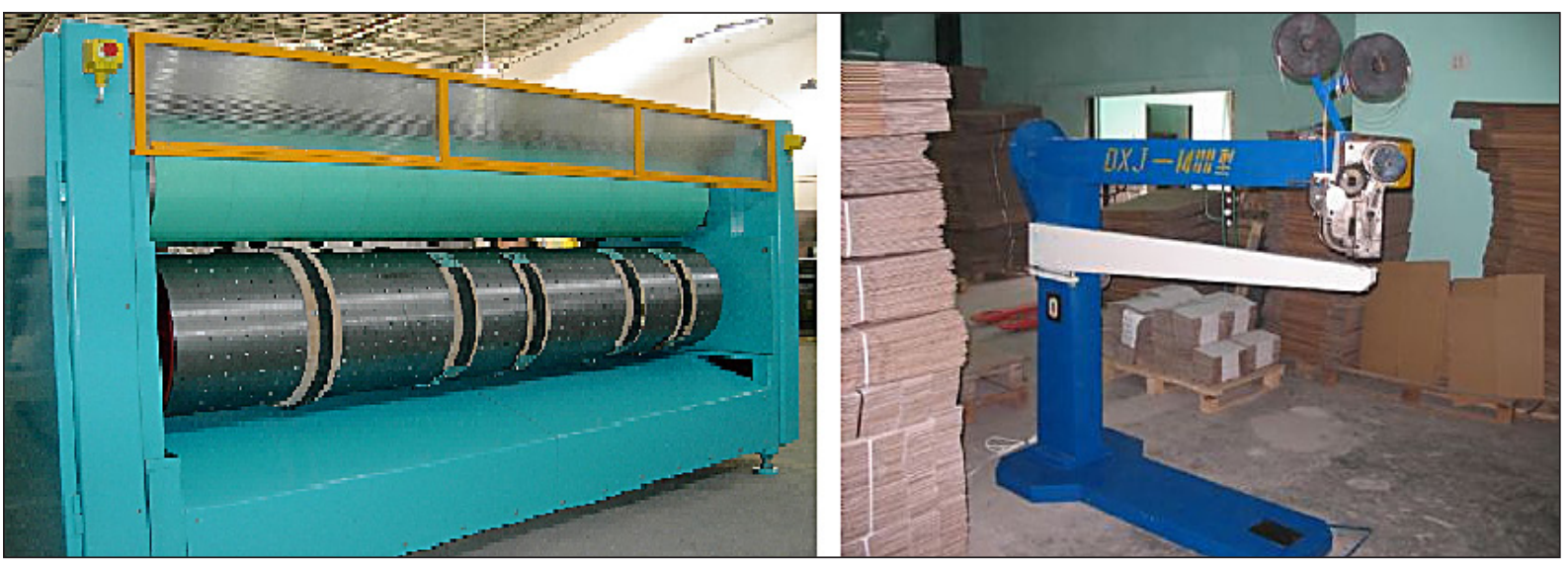

Fig. 4. Technical equipment: a) rotary die cutter, b) flat-wire stitcher

Finally, the technical equipment includes a folder gluer (Fig. 5a) and an assortment of dies of different dimensions (Fig. 5b).

A compact folder gluer in-line system enables automated gluing of a range of cardboard packaging products. At a line speed of $80 \mathrm{~m} / \mathrm{min}$ the machine is suitable for high-quantity orders, whereas easy setting procedures make it fit for a low-cost production company.

\section{Facility layout and material handling}

The layout of machines at the plant of the analysed company is presented in Figure 6. The process chart is shown in Figure 7 and a work transport diagram is shown in Figure 8.

Flow diagram is a graphical representation of the route of work, technical equipment (e.g. transportation vehicles) or workers. The documentation is prepared based on the diagram of the plant layout. Next, based on the observation of transportation of work between locations, the moves of the work or a finished product are marked. In order to achieve clarity of description the symbols were limited to:

- operation,

- inspection,

- transportation,

- inventory.

With a view to complementing the flow diagram, an additional work transport (with in-house transportation vehicles) diagram was produced. Both diagrams provide data on the frequency of transfers of the material, the points of intersection and types of operations carried out along the route. Moreover, these provide information on exact places of particular operations as well as machines and equipment used.

\section{SUGGESTED IMPROVEMENTS}

\section{Aim and scope of improvements}

The purpose of suggested improvements is to increase the competitiveness of both goods pro-

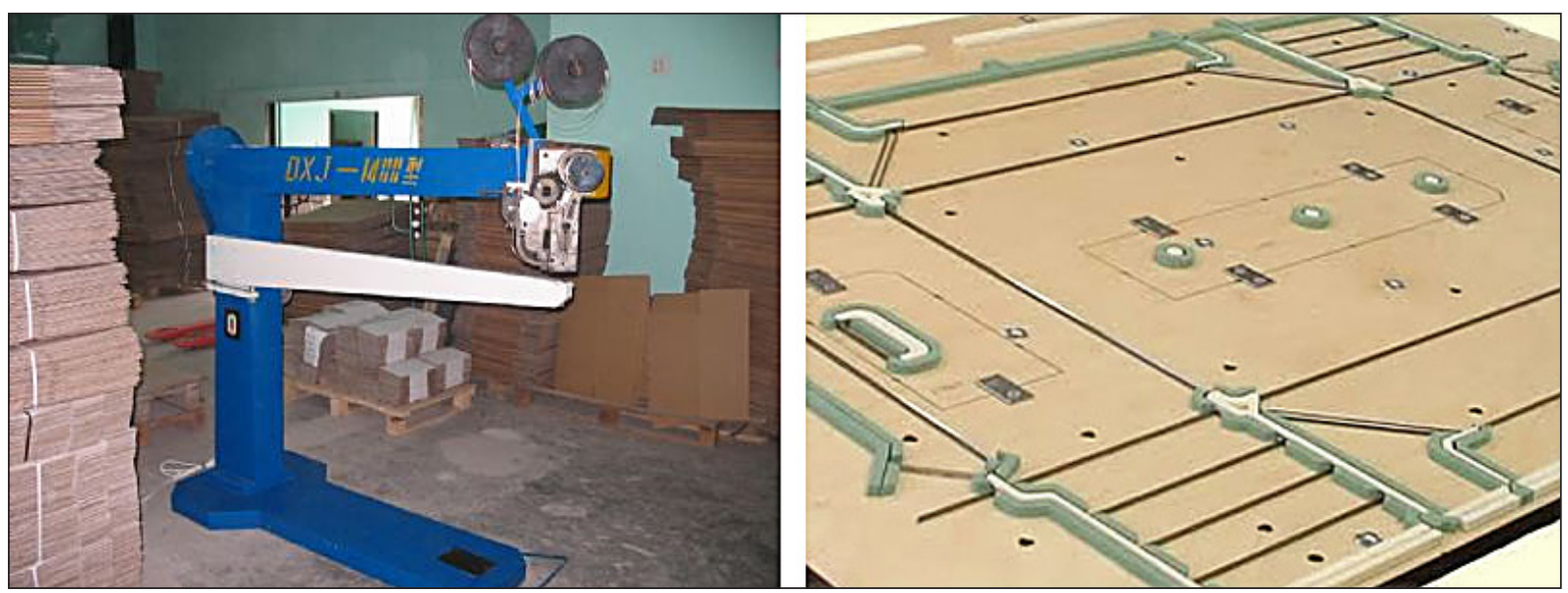

Fig. 5. Technical equipment: a) folder gluer, b) die 


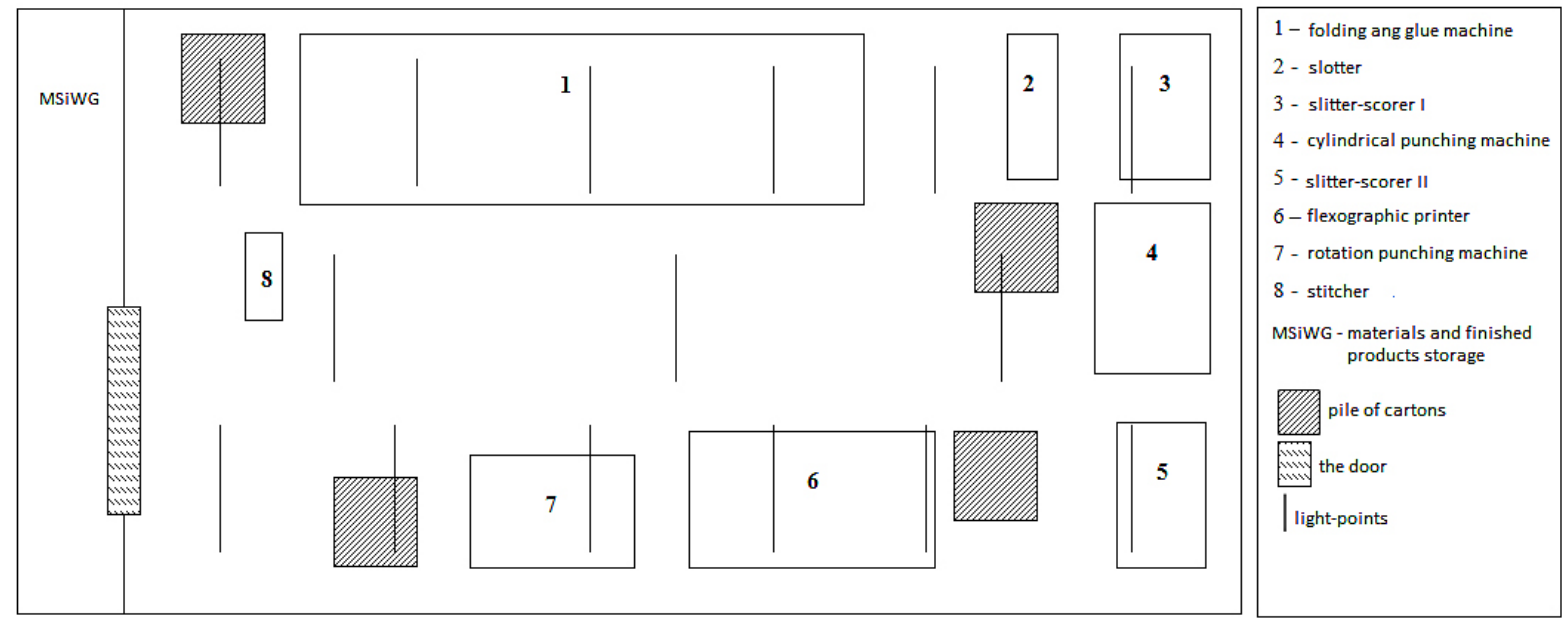

Fig. 6. Current layout of machines at the production facility
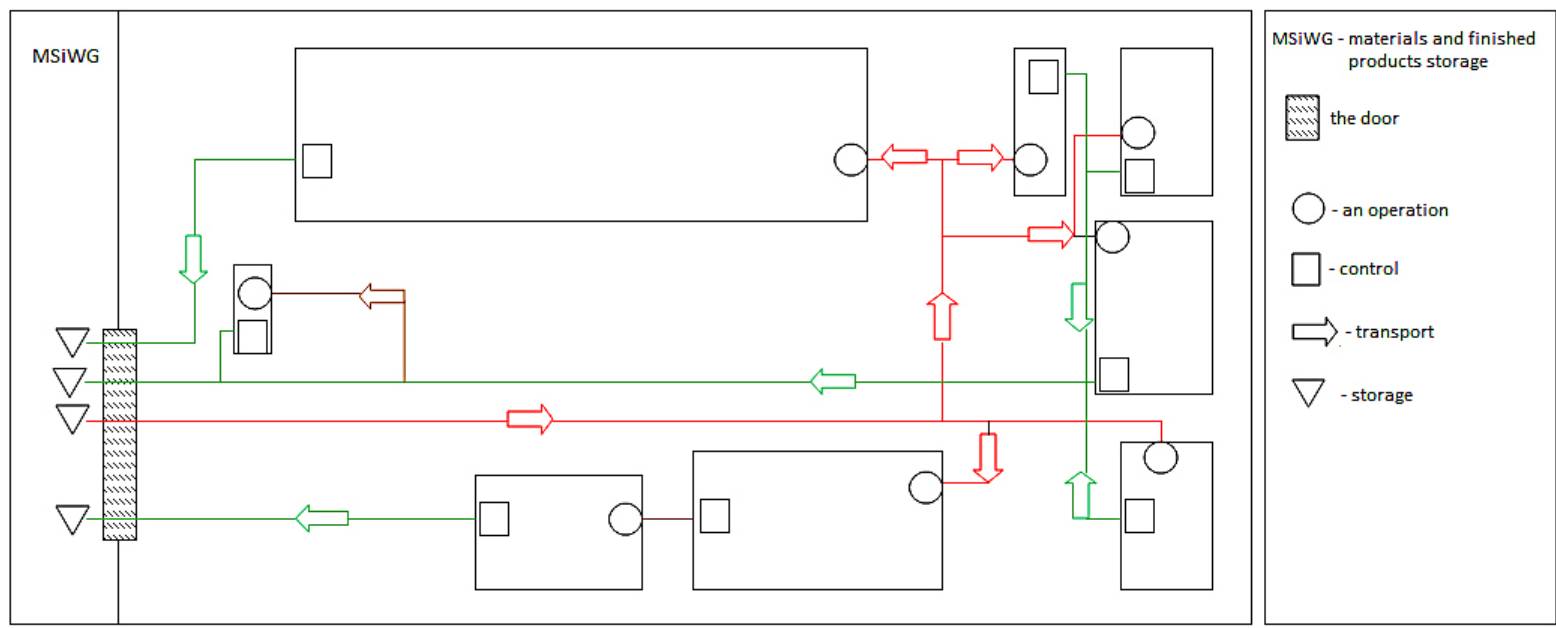

Fig. 7. Current flow diagram at the production facility
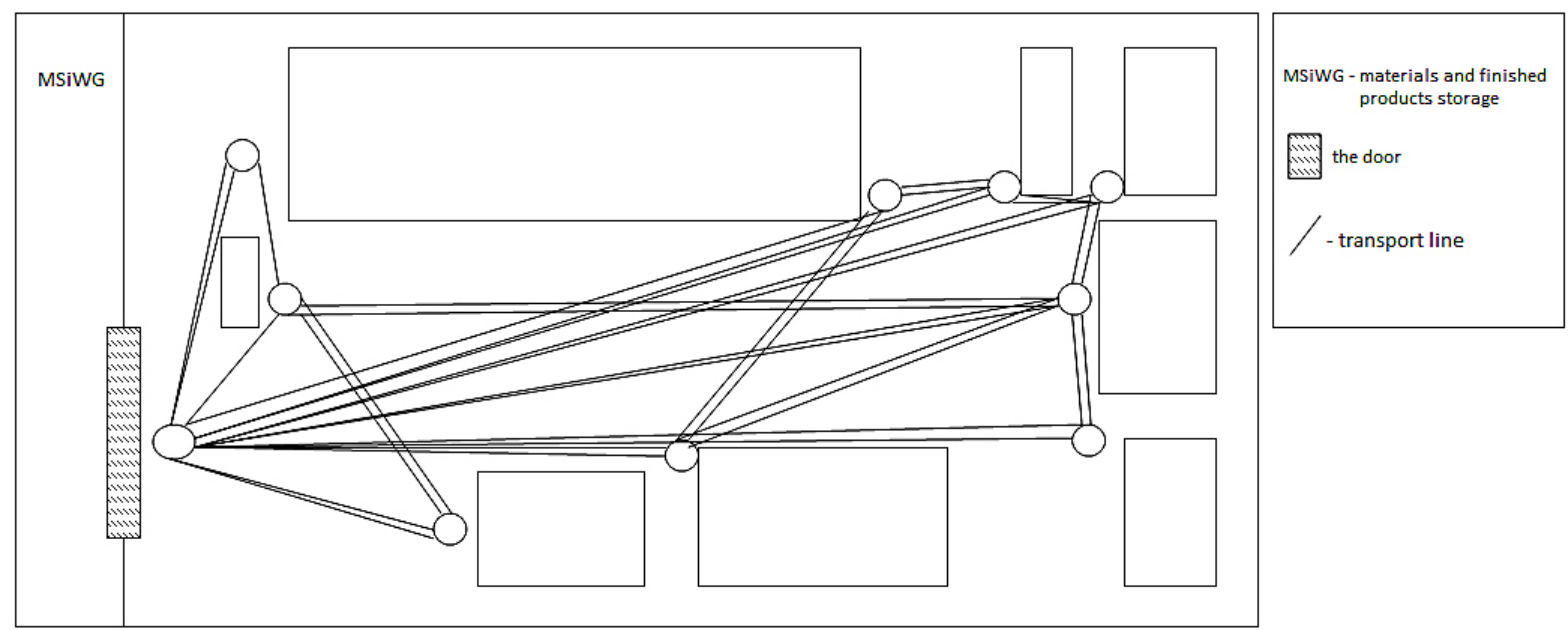

Fig. 8. Current work transport diagram at the production facility

duced by INTERPAK and the company itself, which will result in deeper penetration of the market and further development. The improvement of the company operation requires implementing changes in, inter alia, the technical and organisational field. The proposed course of action is an attempt to reformulate the current methods of operation and solutions. 


\section{Technical and technological improvements}

The technological face of each company is of great significance, as it determines to a considerable extent its supply capabilities. The proposed technical changes cover the purchase of technical equipment to improve the company supply capabilities and expand the selection of products offered by the company. The facilitation of production includes introduction of new production machines, which would partly substitute current equipment.

The suggested purchases are based on a thorough analysis of technical parameters of selected machines so as to correspond the profile of production. The suggested purchases are three machines:

- ZYM Automatic Rotary Die Cutting Machine - capable of creasing, slitting, cutting out perforation, slots and flaps. Automated feed with vacuum suction system and phase adjustment is set with planetary gears system. The die cutting machine is equipped with an energy-efficient speed regulation system with an inverter to adjust the main motor, as well as back and front control panels.

- Boxmat 2400 (Fig. 9) - an automatic slottedtype box making machine, for low- and highquantity production of slotted-type boxes. It is a perfect solution for producers of collective packages of different dimensions. The machine enables production of unlimited types and quantity of boxes by entering basic box dimensions (length, width, height), the remaining dimensions, including trim allowance, being automatically calculate $0 \mathrm{~d}$ by the computer.

- rotary die cutter Model TB (Fig. 10) - performing cutting and bending on corrugated cardboard. Enabling a wide variety of styles,

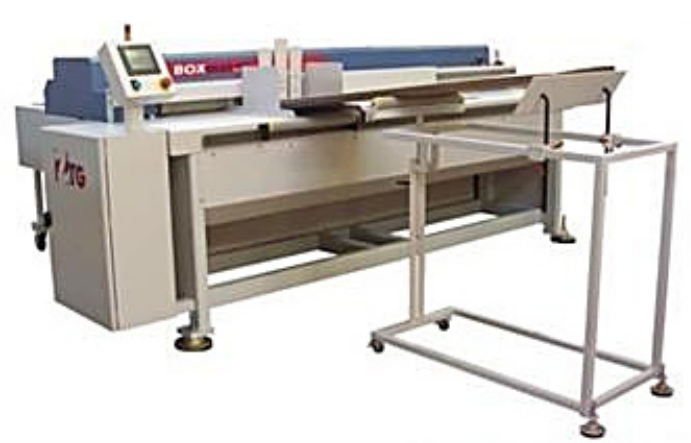

Fig. 9. Boxmat 2400 - automatic slotted-type box making machine [20]

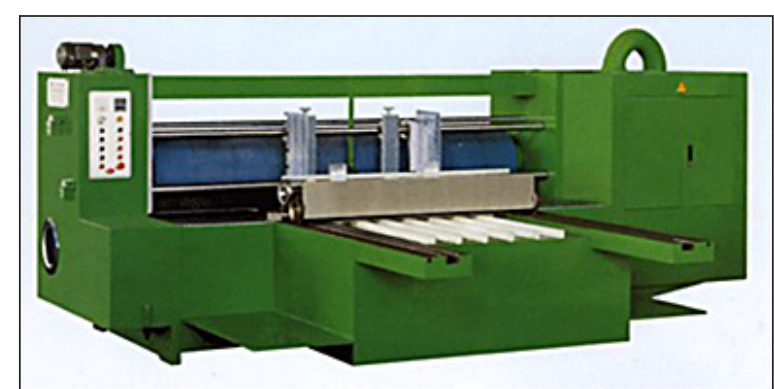

Fig. 10. Rotary die cutter Model TB [21]

the machine is characterised by high-precision cutting, time-effectiveness and simplicity of operation.

Implementation of technical improvements must involve the modernisation of current workstations and in certain cases even the whole technological process.

\section{Organisational improvements}

Organisational changes constitute a key element of functioning of any company and are of great impact on the development of an enterprise. Proposed organisational improvements in the analysed small-sized enterprise are not as substantial as the technical solutions. The implementation of organisational improvements will require raising qualifications of the staff through vocational training. Introduction of new machinery and equipment will necessitate employing new workers. Personnel qualifications should be raised by organising additional training for the management, production supervisors and production workers.

Another important task is to provide a clearly defined job description for each of the employees. Doing so is an important step towards raising work effectiveness.

Organisational improvements are also aimed at aiding the development of the enterprise and for smooth operation of the whole company.

What should be also improved is the company recognition. This can be achieved by placing the company business card, logo and details, on three major polygraph online directories (e.g. plastech.pl).

Furthermore, it is important for a company to maintain a broader perspective, which can be achieved by developing a 7-10-year-long marketing plan. This will introduce stability into the company's marketing endeavours. The 
essential marketing expenses are estimated at several million Polish zlotys and would otherwise be prohibitive for a micro-enterprise. Spreading the necessary investments and the marketing plan over the period of 7-10 years will bring positive effects. Firstly, it will allow realisation of marketing undertakings according to plan. Secondly, it will enable creation of a strong brand and build the identity of the company on the market.

Due to the lack of own specialised human resources, marketing activities should be outsourced. For that reason, a professional marketing agency should be employed.

The identity of the company can be also built by attendance in European-wide events, such as Poznań International Fair.

Considering all the aforementioned, in order for the company to progress there are several crucial organisational improvements to be implemented:

1. Intensification of marketing activities in the aspect of:

- placing the business cards on several polygraph online directories - nowadays it is possible to put such data on websites free of charge,

- employing a professional marketing agency to design a campaign for the years to come.

2. Participation in European-wide polygraph trading events (e.g. Poznań International Fair) (maximum cost 30,000 PLN).

3. Raising qualifications of the staff through training.

\section{Improvement of facility layout}

Proper layout of units in a production system is essential to its functioning. It consists in distributing and ordering the components so that several conditions are secured: rational use of production space, uncomplicated production process and transport minimisation. The production space is organised through arranging a network of technological, operational and information processes. Designing the spatial organisation of production processes must follow certain criteria, such as:

- the number or means of transport,

- the number of transport operations,

- optimal use of production space,

- maximum work safety,

- equipment installation and operation costs.

\section{Workstations layout}

The more automated the basic production processes in a company are the more modernised workstations this requires. This is connected, among other things, with implementing automated machines, which do not require constant operation and in the case of which the employee's work consists in control and supervision. The layout of machines and equipment realising the production process predominantly depends on the structure of the production system. The spatial structure of the production system is governed by:

- the sequence of a production process

- the degree of integration of a production process.

Moreover, while designing the layout of workstations at the facility of a company attention must be paid to securing:

- full coordination of worker activities,

- free material flow,

- full coordination of machine work and worker activities,

- minimum distance for a material to travel between subsequent operations,

- employee satisfaction with work conditions and safety,

- flexibility of workstations arrangement (accounting for the planned modernisation of the company in the future years).

The improvements will be implemented to facilitate the production process, reduce costs and use the production resources more effectively. A proposed layout for the production plant of the analysed producer, designed according to the technical and organisational plan of improvements, is shown in Figure 11.

The proposed improvement of workstation layout involves the machines currently in operation. In addition, the changes will require configuring the arrangement of machines which should be bought as a part of investments. The scope of changes involves such machines as: slotter, cardboard bending machine, printer and stitcher. Compared with the current layout, the location of the folder gluer will remain unchanged.

The main reason for changes introduced to the current layout of the machines is complicated material flow and as a result the transportation vehicle path. 


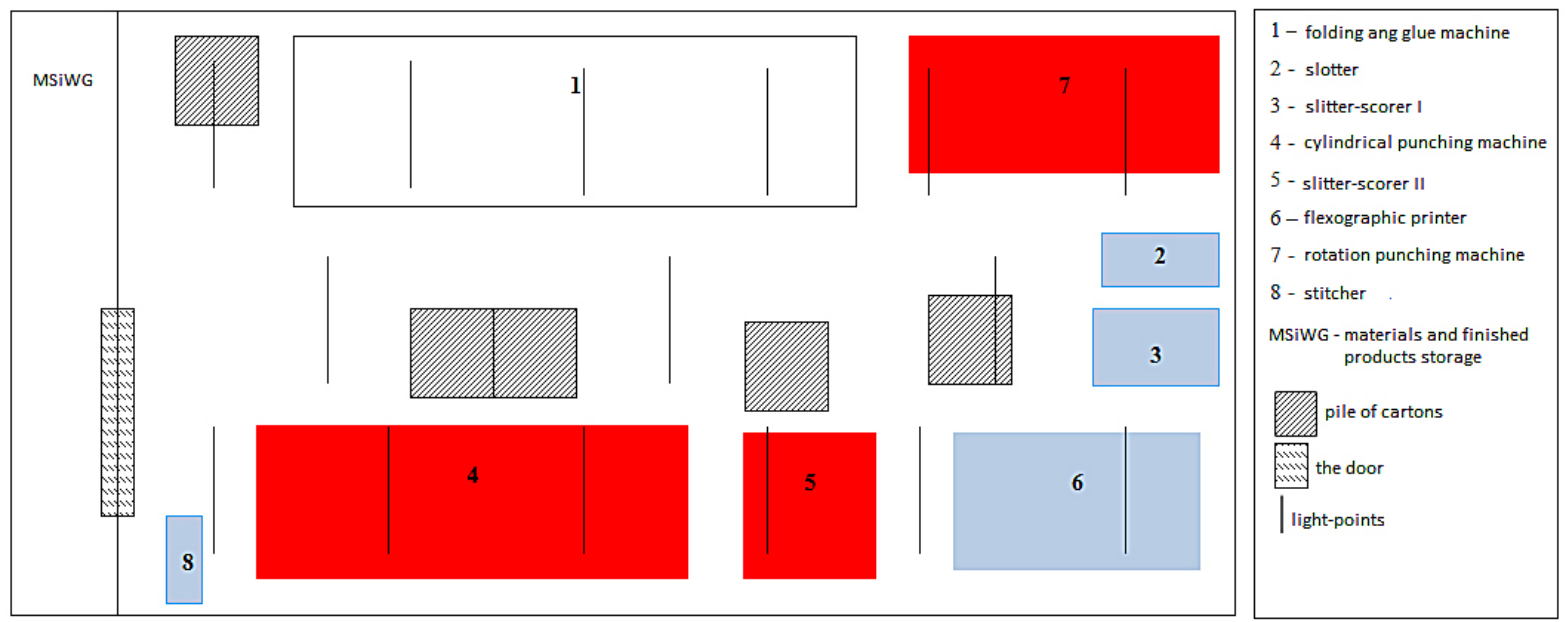

Fig. 11. Machine layout at INTERPAK production plant (after modernisation)

\section{Improvement of material flow and work transport}

The changes of layout of workstations in the plant necessitate the update of material flow and work transport diagrams. Due to the current machine layout at the analysed plant, this is the material flow and the work transport which were considered as key factors of any suggested changes. Transportation in the production process consists of all the actions connected with movement of material. Work transport (with in-house transportation vehicles) causes changes of storing place, handling of raw materials, semi-finished and finished products. However, it also involves the movement of workers over the plant.

The observation of transportation involved analysing and recording each point of transportation vehicle. Subsequently, particular points were linked, as well as all the repetitions of the route.
Flow diagram and work transport diagram are shown in Figure 12 and Figure 13.

Essential analysis proved that the parts of work path of the heaviest traffic were reduced to minimum or eliminated. The improvements in the material flow and work transport are crucial to the rhythmical work of the plant and particular work cells. These efforts lead to shortening the production time, ergo increase of efficiency. The proposed technical changes will furthermore minimise the workload on each particular worker and improve work safety.

\section{EXPECTED EFFECTS OF IMPROVEMENTS}

Implementation of suggested changes in the production company is to bring concrete and predefined advantages. These include, e.g. higher profits, competitive advantage, increased supply,

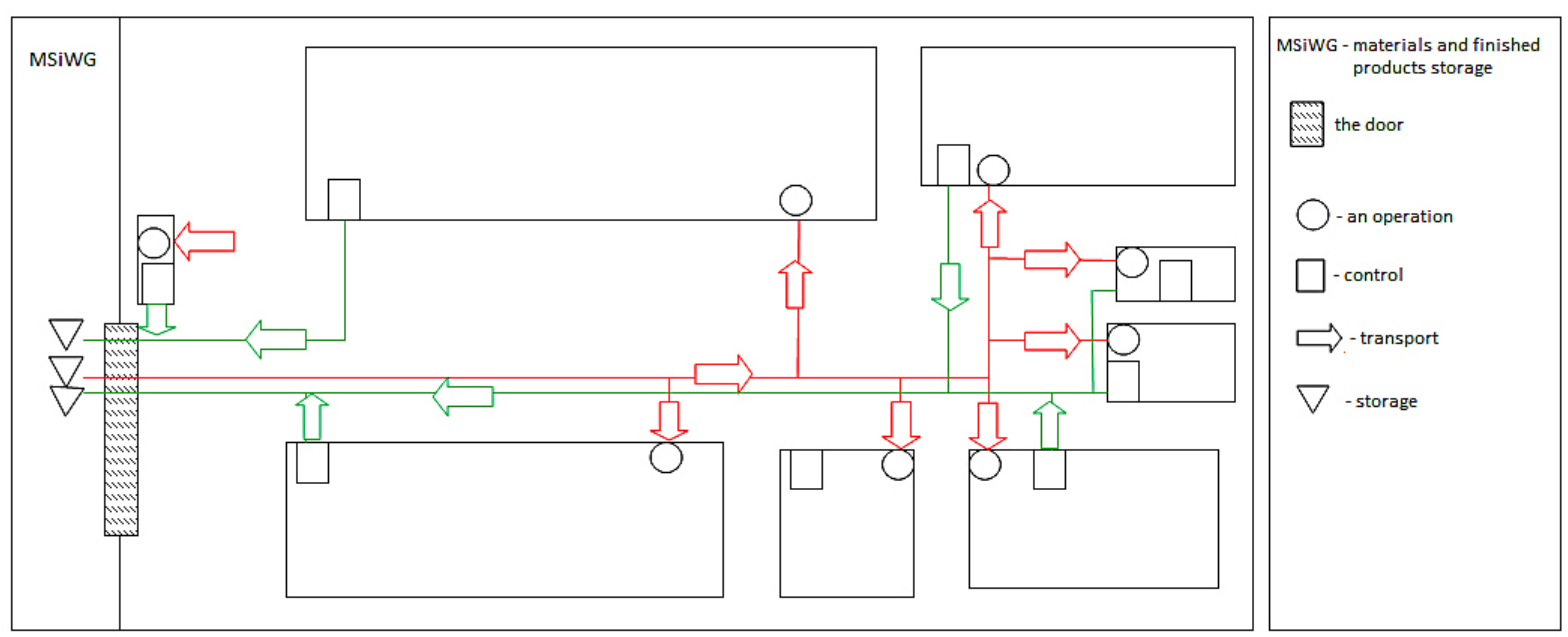

Fig, 12. Flow diagram at the production facility (after modernisation) 


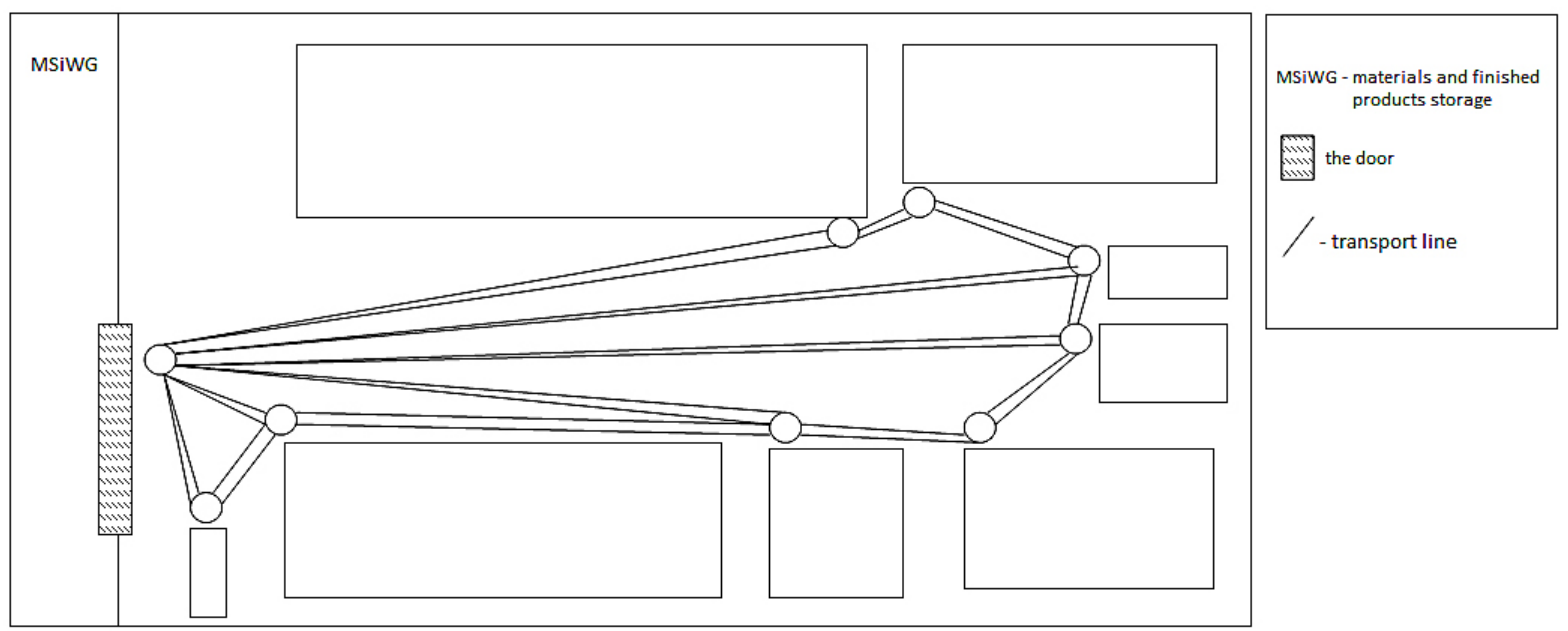

Fig. 13. Work transport diagram at the production facility (after modernisation)

higher organisational culture etc. Achieving these goals is a prerequisite for further changes and development of organisation.

\section{Technical and technological improvements}

Technical improvements in the analysed company consist in purchasing new machines. The expectations are that this investment will predominantly increase the production efficiency and supply. Modern technologies implemented in the production process will give the company advantage over the competition and enable them to fulfil the increasing demands of clients. Automation of selected stages of the technological process will streamline the production by, inter alia, shortening the production cycle and improving the efficiency in the use of manufacturing resources.

In addition, modernisation of the production hall and improvement of the layout of machines and equipment will allow faster flow of material and finished product, which will in turn contribute to increasing the production process efficiency. Spatial organisation of particular processes of a production system brings another advantage in the form of shortening the production cycle, reducing production costs and better use of production resources.

\section{Organisational improvements}

Launching a product onto a market requires decisions in the area of brand building and company recognition. This aspect of company operation will mainly involve the participation in trade fairs and placing company details on renowned websites. The progress of online advertising tech- nologies opens the possibilities of reaching thousands of potential customers, as the numbers of regular Internet users and online shoppers are on the increase.

\section{CONCLUSIONS}

Technical and organisational changes are essential to the survival and further development of every enterprise. Organisations focused on constant development should gain competitive advantage and manage the shocks of sudden market fluctuations. This forecasting is made possible by innovation and different advances. Continuous collaboration between authors and recipients of innovative solutions creates conditions promoting out-of-the-box thinking in technology, product and organisational aspects. It fosters sharing experiences and increases the efficiency of resources employed by each cooperating party.

The paper shows that the conducted analysis, which was concluded in formulation of a series of recommendations, together with application of the proposed improvements should open the gate to realisation of the company goals. The suggested purchases of machines earmarked for the character of production will positively impact the manufacturing efficiency and supply capabilities of the company. This will enable the enterprise to reach new markets. Finally, marketing efforts, i.e. advertising and participation in trade fairs, are intended to boost brand recognition, reach new groups of clients and to establish the position of the company on local and national markets.

Among the technical and technological recommendations the most important ones are: 
- automation of certain elements of the production process (increased efficiency, lower material consumption, higher quality) - new machines and equipment - approx. 1.0 million PLN;

- changes in production plant layout: arrangement of machines and equipment at the production facilities (to improve material and finished product flow).

Implementation of planned organisational changes will contribute to creating effectively working structures within the company, and should therefore increase its efficiency. Boosted supply and more clients will enable the development of the company in the future. Introducing a complete array of recommended improvements should reinforce the position of the company on the market and enable withstanding the aftermath of the economic crisis and the pressure of the competition.

\section{REFERENCES}

1. Banaszak Z., Zaremba M., Muszyński W. Constraint programming for project driven manufacturing. International Journal of Production Economics, 120, 2009, 463-475.

2. Bocewicz G., Nielsen I., Banaszak Z. Iterative multimodal process scheduling. Annual Reviews in Control, 38 (1) 2014, 113-132.

3. Bromiley P., Rau D. Operations management and the resource based view: Another view. Journal of Operations Management, 41, 2016, 95-106.

4. Bulak M., Turkyilmaz A. Performance assessment of manufacturing SMEs: A frontier approach. Industrial Management \& Data Systems, 114 (5), 2014, 797-816.

5. Gola A., Świć A. Computer-Aided Machine Tool Selection for Focused Flexibility Manufacturing Systems Using Economical Criteria. Actual Problems of Economics, 124 (10), 2011, 383-389.

6. Gola A., Świć A. Economic analysis of manufacturing systems configuration in the context of their productivity. Actual Problems of Economics, 162 (12), 2014, 385-394.

7. Kádár B., Terkaj W., Sacco M. Semantic Virtual Factory supporting interoperable modelling and evaluation of production systems. CIRP Annals
Manufacturing Technology, 62 (1), 2013, 443-446.

8. Kłosowski G., Gola A., Świć A. Application of Fuzzy Logic Controller for Machine Load Balancing in Discrete Manufacturing System, Lecture Notes in Computer Science, 9375, 2015, 256-263.

9. Relich M. Fuzzy project scheduling using constraint programming. Applied Computer Science, 9 (1), 2013, 3-16.

10. Relich M., Bzdyra K. Estimating new product success with the use of intelligent systems. Foundations of Management, 6 (2), 2014, 7-20.

11. Relich M., Świć A., Gola A. A Knowledge-Based Approach to Product Concept Screening. Advances in Intelligent Systems and Computing, 373, 2015, 341-348.

12. Rudawska A., Seń A., Semotiuk L. Technical and organizational aspects of production preparation on the example of door factory. Advances in Science and Technology, 7 (20), 2013, 42-46.

13. Shah R., Ward P.T. Defining and developing measures of Lean Production. Journal of Operations Management, 25 (4), 2007, 785-805.

14. Sharma A. Collaborative product innovation: integrating elements of CPI via PLM framewerk. Computer-Aided Design, 37, 2005, 1425-1434.

15. Sirmon M.A., Hitt R.D. Managing firm resources in dynamic environments to create value: looking inside the black box. Academy of Management Review, 32 (1), 2007, 273-292.

16. Sitek P., Wikarek J., A novel approach to decision support and optimization of group job handling for multimodal processes in manufacturing and services. IFAC - PapersOnLine 48 (3) 2015, 2115-2120.

17. Smith F.I., Stone T.H., Kisamore J.L., Jawahar I.M., Decision-making biases and affective states: their potential impact on best practice innovation, Canadian Journal of Animal Sciences, 27, 2010, 277-291.

18. Sobaszek Ł., Gola A. Computer-aided production task scheduling. Applied Computer Science, 11 (4), 2015, 58-69.

19. Ungan M. Management support for the adoption of manufacturing best practices: key factors. International Journal of Production Research, 43 (18), 2005, 3803-3820.

20. Source: http://www.scorpio.com.pl/PL/Oferta/ Category/17/Product/328/Default.aspx, accessed: 2016.02.03.

21. Source: http://www.paker.eu/index.php?k=maszy ny\%20sztancujace, accessed: 2016.02.03. 